\title{
STUDY OF TH1/TH2 BALANCE IN PERIPHERAL BLOOD MONONUCLEAR CELLS OF PATIENTS WITH ALOPECIA AREATA
}

\author{
SOHA SADEGHI ${ }^{1}$, MOHAMMAd HoSSEIN SANATI ${ }^{1}$, \\ MORTEZA TAGHIZADEH ${ }^{2}$, \\ PARVINE MANSOURI ${ }^{3}$ and ZOHREH JADALI ${ }^{3,4 *}$ \\ ${ }^{1}$ Clinical Genetics Department, National Institute of Genetic Engineering \\ and Biotechnology, Tehran, Iran \\ ${ }^{2}$ Razi Vaccine and Serum Research Institute, Karaj, Iran \\ ${ }^{3}$ Skin and Stem Cell Research Center, Tehran University of Medical Sciences, Tehran, Iran \\ ${ }^{4}$ Department of Immunology, School of Public Health, \\ Tehran University of Medical Sciences, Tehran, Iran
}

(Received: 26 January 2015; accepted: 17 June 2015)

\begin{abstract}
Alopecia areata represents an autoimmune pathological process driven primarily by cellular aberrations contained within the immune system, which activates various humoral and cellular elements of the immune response. The aim of this study was to determine the mRNA expression levels of T-bet and GATA-3 as potential inducers of $\mathrm{T}$ helper (Th) 1 and Th2 differentiation, respectively, as well as Th1(IFN- $\gamma$ ) and Th2(IL-4) cytokine mRNA expression in patients with alopecia areata. Using real-time reverse transcriptase PCR (RT-PCR), the relative amounts of T-bet, GATA-3, IFN- $\gamma$, and IL-4 mRNA transcripts were determined in PBMCs from 20 Iranian patients with alopecia areata and compared with those of 20 healthy control subjects. In comparison with the normal group, T-bet and IFN- $\gamma$ mRNA expression levels were significantly up-regulated in the alopecia areata patients, while GATA-3 and IL-4 mRNA expression levels were down-regulated. Notably, positive correlation $(\mathrm{P}<0.05)$ was found between IFN- $\gamma$ and $\mathrm{T}$-bet levels in patients and controls. In addition, significant positive correlations existed between GATA-3 and IL-4 $(\mathrm{P}<0.05)$. These results indicate that a Th1/Th2 imbalance exists in alopecia areata, and it may be implicated in the pathogenesis of disease.
\end{abstract}

Keywords: alopecia areata, T lymphocyte, autoimmunity, cytokine

*Corresponding author; E-mails: zjadali@razi.tums.ac.ir, zjadali@yahoo.co.uk 


\section{Introduction}

Alopecia areata (AA) is a common, chronic, inflammatory disorder which typically causes an unpredictable, non-scarring form of hair loss and affects almost $0.1 \%$ of the general population [1]. Although the aetiology of AA is poorly understood, current evidence proposes that alterations in T-cell subpopulations and abnormality of their cytokine expression may contribute to the disease pathogenesis [2]. Therefore, one of the most important issues in the proper interpretation of the immunological alterations in AA is to determine the variations of T-lymphocyte subsets in affected patients.

In humans, different T-cell subpopulations can be recognized in peripheral blood and other tissues on the basis of molecular markers and distinct cytokine profiles. Among those, special attention has been paid to two types of functionally different CD4+ T helper cell subsets known as T helper 1 (Th1) and T helper 2 (Th2).

Increased or unbalanced activation of Th1 or Th2 subgroups, not only compromise normal immune system function and haemostasis but also promote and support the development of AA. However, there is controversy in the literature about AA being a Th1 or Th2 autoimmune phenomenon, or both [3-6]. Thus, identifying the molecular switches that regulate differentiation of CD4+ T cells into Th1 and Th2 effector cells in diseased subjects is the keystone for the characterization of the errors in the function of the immune system. In another word, aberrations of the molecular mechanisms underlying Th differentiation may affect the susceptibility to AA.

To date, the complete program of Th1/Th2 differentiation is not definitively known. There is growing evidence to suggest that two transcription factors, T-box expressed in T cells (T-bet) and guanine adenine thymine adenine sequence-binding protein 3 (GATA-3), are the determining factors of Th1 and Th2 development, respectively [7, 8]. These cells also display a unique and different cytokine pattern. Th1 cells that produce interferon- $\gamma$ (IFN- $\gamma)$, IL-2 and tumour necrosis factor- $\beta$ (TNF- $\beta$ ), are involved in cell-mediated immunity. Whereas Th2 cells enhance humoral responses and their activities are accompanied by the production of cytokines such as IL-4, IL-5, IL-13 and IL-10 [9]. In addition, these lymphocyte groups have counterregulatory effects against each other predominantly by means of the IL-4-IFN- $\gamma$ negative feedback loop [10].

The goal of this research was, (1) to determine T-bet, GATA-3, IFN- $\gamma$, and IL-4 mRNA expression patterns in PBMCs of patients with AA and healthy control subjects, (2) analysis of correlation between T-bet/GATA-3 and IFN- $\gamma /$ IL-4 to understand the potential role of these two transcription factors in signalling for the differentiation of Th1/Th2 lymphocytes, (3) to evaluate whether there 
was a difference in cytokine gene expression patterns (IFN- $\gamma$, and IL-4) among control group and patients.

\section{Materials and Methods}

\section{Patients and controls}

Peripheral venous blood specimens were drawn from 20 patients with AA (11 men, 9 women) in dermatology clinics. All of the individuals were treatment free for a minimum of four weeks before entering the study. All cases were examined for body involvement with alopecia areata. The pattern of hair loss was divided into two groups as follows: Patchy hair loss $(n=19)$ and alopecia totalis (AT: Loss of whole scalp hair; $n=1$ ). The presentation of patients was usually with single or several patches of hair loss with no scales. Nail changes with pitting was observed in $5(25 \%)$ of patients.

Patients were categorized into one of three groupings according to the presence of associated disorders: 13 had no family history of autoimmune diseases and no other disorder, 6 had a family history of autoimmune disorder but had no other diseases, and 1 had an autoimmune disease (vitiligo).

The mean age of the patients in this study was $28.65 \pm 10.12 \mathrm{yr}$ (men $28.73 \pm 13.05 \mathrm{yr}$; women $28.56 \pm 5.53 \mathrm{yr}$ ). Blood samples from 20 healthy subjects (4 men, 16 women) were also used as controls, all of whom had no history of AA or other chronic and autoimmune diseases. The mean age of the healthy volunteers was $30.10 \pm 6.87 \mathrm{yr}$ (men, $35 \pm 9.13 \mathrm{yr}$, women, $28.88 \pm 5.92 \mathrm{yr}$ ).

The protocol was approved by the Research Ethics Board at Tehran University of Medical Sciences. All patients and control subjects had completed informed consent before the start of any study-related procedures.

Plasma was separated by centrifugation at $4{ }^{\circ} \mathrm{C}$, aliquoted, and stored at $-70{ }^{\circ} \mathrm{C}$, until assayed. The stored plasma was used later for quantifying IFN- $\gamma$ and IL-4. PBMCs were isolated from the whole blood by standard density gradient centrifugation using Histopaque (Pharmacia, Uppsala, Sweden) gradient.

\section{Isolation of RNA from PBMCs and reverse transcription}

Approximately $5 \mathrm{ml}$ of fresh EDTA whole blood was collected from patients with AA and normal controls. Total RNA was extracted from PBMCs using RibospinTM (GeneALL, Seoul, Korea). In the next step, the yield and quality of the recovered RNA samples was assessed by agarose gel electrophoresis 
and ethidium bromide staining. In addition, the concentration of RNA was estimated by measuring the absorbance at $260 / 280 \mathrm{~nm}$ in the Nanodrop (Thermo Scientific, USA). Only high-quality RNA, with the absorbance ratio between 200 and $400 \mathrm{ng} / \mu \mathrm{l}$, was used for further experiments.

The first strand cDNA was generated from approximately $1000 \mathrm{ng}$ of RNA using the first strand cDNA synthesis kit (Fermentas, Germany) and stored frozen at $-20{ }^{\circ} \mathrm{C}$ until use.

Quantitative reverse transcriptase polymerase chain reaction (RT-PCR) analysis

SYBR Green I-based one-step real-time quantitative RT-PCR amplification was performed in a RotorGene 6000 (Corbett Life Science, Australia) thermal cycler. We confirmed that non-specific bands were not detected by melting curve analysis for each primer set. Primers specific for T-bet, GATA-3, IFN- $\gamma$, IL-4 and housekeeping gene B-actin were purchased from TAG Copenhagen (Denmark). B-actin gene was used as an internal control to normalize the expression of these genes. The nucleotide sequences of the primers and RT-PCR protocols utilized in this study was explained previously [11].

PCR products were then electrophoresed on an agarose gel in order to determine the presence of a single band with the expected size. Quantitative gene expression data were normalized to the expression levels of the house-keeping $\mathrm{B}$-actin gene. For this reason, $\mathrm{Ct}$ (cycle threshold) value that represents the cycle number in which the PCR products reach the threshold level was applied. The expression level of the target genes were shown as $\Delta \mathrm{Ct}(\Delta \mathrm{Ct}=\mathrm{Ct}$ value of the target gene $-\mathrm{Ct}$ value of the $\beta$-actin gene). All statistical analyses were carried out on $\Delta \mathrm{Ct}$ values. Higher $\Delta \mathrm{CT}$ values express lower mRNA levels.

\section{Statistical analysis}

Student's $t$ test was used for comparing sample results with a known value. Correlations between the different variables were assessed by Pearson test. P-values lower than 0.05 were considered statistically significant. Results are expressed as means \pm SD. 


\section{Results}

Detection of transcription factor gene expression

The expression levels of transcription factors for Th1 (T-bet) and Th2 (GATA-3) were directly analysed on PBMCs by means of quantitative real-time PCR (Figs 1 and 2). This revealed a significantly higher T-bet mRNA expression level in patients' PBMCs $(-1.25 \pm 5.13)$ compared with controls $(5.04 \pm 4.70)$. On the contrary, reduced GATA-3 expression was observed in patients' samples (4.29 \pm 3.83$)$ compared with controls $(1.74 \pm 5.19)$.

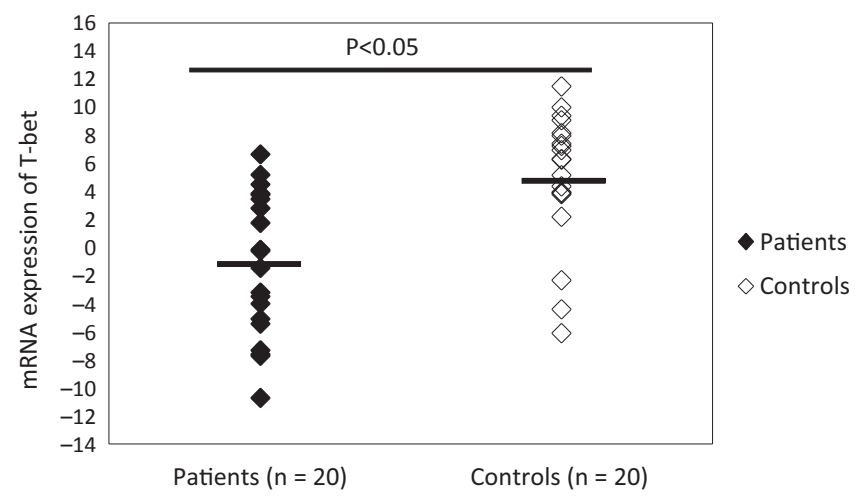

Figure 1. mRNA expression levels for T-bet in patients and control subjects. $\beta$-actin was used as the internal control.

Please note that a higher $\Delta \mathrm{Ct}$ value corresponds to a comparably lower expression level

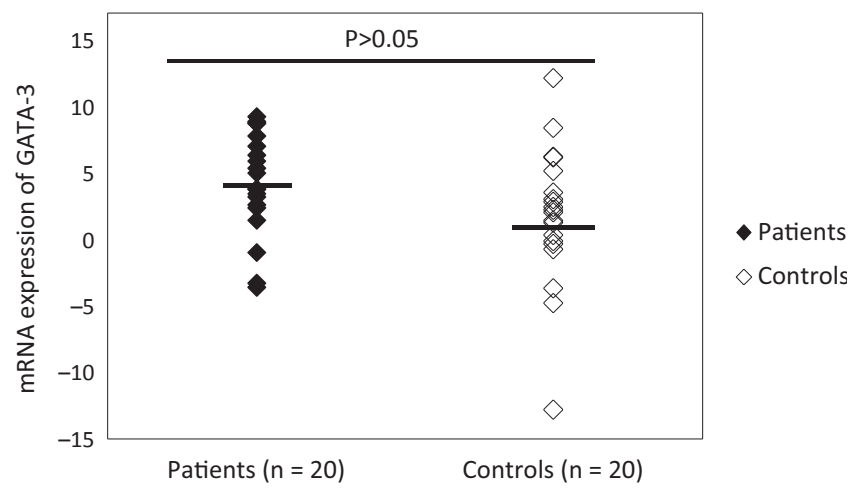

Figure 2. mRNA expression levels for GATA-3 in patients and control subjects. $\beta$-actin was used as the internal control.

Please note that a higher $\Delta \mathrm{Ct}$ value corresponds to a comparably lower expression level 


\section{Detection of cytokine gene expression}

Differences in Th1/Th2 cytokine pattern were assessed at the mRNA level between patients and controls (Figs 3 and 4). To explore the role of IFN- $\gamma$ and IL-4 in Th mediated autoimmune pathology of AA, we evaluated the variations of mRNA levels of Th1-type cytokine (IFN- $\gamma$ ) and Th2-type cytokine (IL-4) in patients and controls. As indicated in Fig. 3, the level of IFN- $\gamma$ mRNA were significantly increased in patients $(-2.24 \pm 3.40)$ compared with healthy subjects $(2.80 \pm 4.26)(\mathrm{P}<0.05)$. In contrast, IL-4 mRNAs were significantly reduced in the PBMCs from patients (4.11 \pm 4.85$)$ as compared to normal controls (1.02 \pm 3.87$)$.

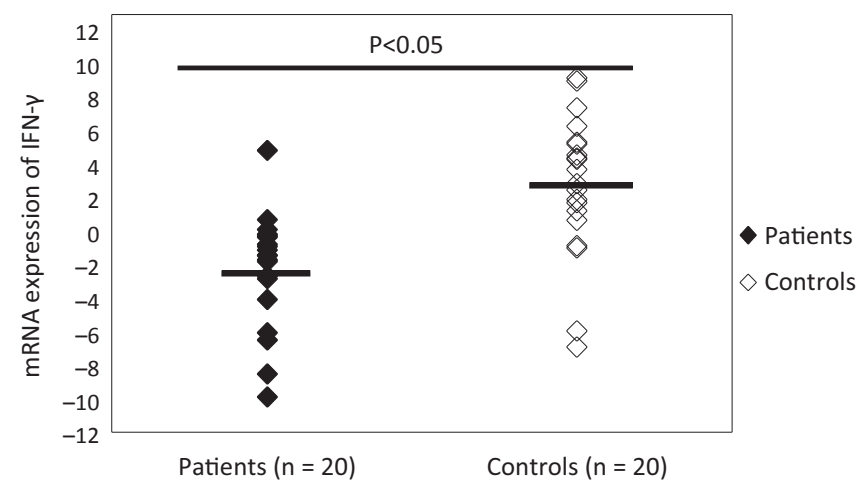

Figure 3. mRNA expression levels for IFN- $\gamma$ in patients and control subjects. $\beta$-actin was used as the internal control.

Please note that a higher $\Delta \mathrm{Ct}$ value corresponds to a comparably lower expression level

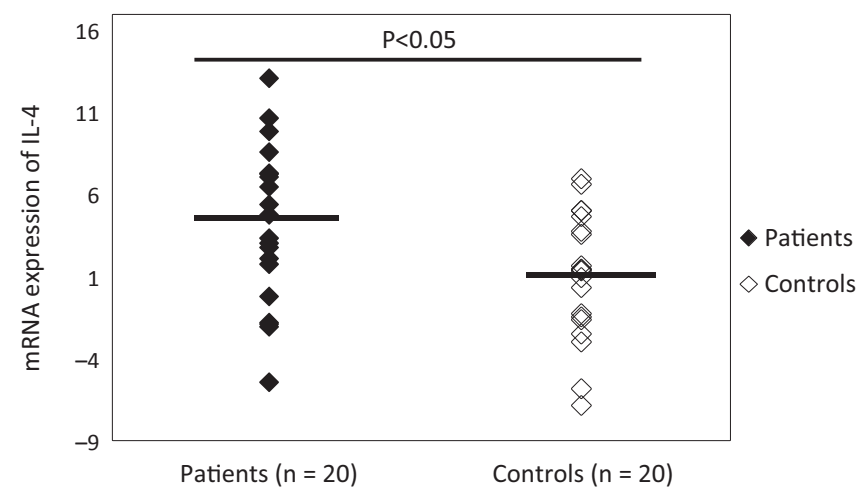

Figure 4. mRNA expression levels for IL-4 in patients and control subjects. $\beta$-actin was used as the internal control.

Please note that a higher $\Delta \mathrm{Ct}$ value corresponds to a comparably lower expression level 
In addition, there was significant positive correlation between T-bet and IFN- $\gamma$ mRNA levels $(r=0.463, \mathrm{P}<0.05)$, and of GATA-3 with IL-4 $(\mathrm{r}=0.635, \mathrm{p}<0.05)$. The same type of correlation was also observed in control subjects $(\mathrm{P}<0.05)$.

\section{Discussion}

$\mathrm{AA}$ is a disease of the hair follicles and responsible for $0.7 \%$ to $3.8 \%$ of dermatology clinics visits [12]. In spite of the attempts to reveal the pathophysiology behind this disease, it still remains an enigma. Over the years, several mechanisms underlying AA (such as autoimmunity, environmental factors and genetic predisposition) have been proposed. Among them, great attention has been focused on the autoimmunity. Multiple lines of evidence have demonstrated that immune system disturbances and breakdown of T cell tolerance are the key players in the pathogenesis and development of AA $[13,14]$. Moreover, it is now accepted that the imbalance of Th1/Th2 immunity becomes the cause of various immune diseases including AA [15-17].

In another word, the aberration of Th1/Th2 ratio may be linked to the pathogenesis of AA. Therefore, the purpose of this study was to determine the expression pattern of T-bet and GATA-3 as the master regulators of Th1 and Th2 lineage commitment, respectively. The results of our study demonstrate a significant increase in T-bet mRNA expression level in PBMCs of patients compared to normal controls. In addition, gene expression of GATA-3 was lower (2.5 fold) in patients compared with healthy subjects, although this was not statistically significant.

These results are in agreement with the findings from other researches, with emphasis on the importance of Th1 cells in the pathogenesis of AA. For example, Nakamura et al. indicated the Th1-predominant lymphocytic infiltration around hair follicles of patients with alopecia areata [18]. In another study, Ito et al. demonstrated that patients with acute AA have a higher frequency of circulating CXCR3+ CD4+ Th1 cells [19].

In other part of this study, IL-4 and IFN- $\gamma$ mRNA expression level was evaluated. The main reason for evaluation of Th1 and Th2 cytokine mRNA transcripts was the lack of clear and convincing evidence with respect to the exact role of these cytokines and their contributions in AA pathogenesis [20, 21].

The results of our study indicated a significant increase of IFN- $\gamma$ mRNA expression in patients compared with normal controls $(\mathrm{p}<0.05)$. In contrast, IL-4 mRNA expression was significantly lower in patients than in control subjects $(p<0.05)$. Furthermore, significant correlation between T-bet and IFN- $\gamma$ 
mRNA expression was observed $(\mathrm{p}<0.05)$. We also showed a significant positive correlation between GATA-3 and IL-4 mRNA levels $(\mathrm{p}<0.05)$.

It seems that IFN- $\gamma$ is the key cytokine involved in the pathogenesis of AA [22] and many recent studies point to the connection between elevated levels of serum IFN- $\gamma$ and AA $[23,24]$. These findings are in agreement with other studies demonstrating expanded population of IFN- $\gamma$ expressing cells in PBMC of patients with AA [25].

The possible role of IFN- $\gamma$ in the pathogenesis of AA is further supported by some murine models of skin graft-induced AA. For example, FreyschmidtPaul et al. carried out an impressive study on $\mathrm{C} 3 \mathrm{H} / \mathrm{HeJ}$ mice (a mouse model of AA) with and without a targeted deletion of the Th1 cytokine IFN- $\gamma$ gene. Their results indicate that $90 \%$ of wild-type mice $[\mathrm{IFN}-\gamma(+/+)]$ developed AA, after grafting alopecia areata-affected skin, while none of the IFN- $\gamma(-/-)$ mice exhibited hair loss [26]. Moreover, it has been reported that local injections of both IL-4 and neutralizing anti-IFN- $\gamma$ antibody effectively treated alopecia in $\mathrm{C} 3 \mathrm{H} /$ HeJ mice [27].

Considering the above mentioned findings, it seems plausible to claim that IFN- $\gamma$ plays a pivotal role in the pathogenesis of AA. IFN- $\gamma$ may affect the disease process through multiple potential mechanisms of action, including collapse of the hair follicle immune privilege. It was indicated that IFN- $\gamma$ is the most effective inducer of ectopic MHC class I expression in murine anagen hair bulbs in vivo [28]. Moreover, Paus et al. has been reported that systemic treatment of genetically susceptible $\mathrm{C} 3 \mathrm{H} / \mathrm{HeJ}$ mice with IFN- $\gamma$ accelerated development of AA. They proposed that disease progression may be associated with aberrant expression of MHC class I and class II in the follicular epithelium [29].

Similar to IFN- $\gamma$, evidence for the role of IL- 4 in AA is complex. For instance, Teraki et al. indicate increased IL-4 production in patients with the localized AA [30]. Another study revealed elevated serum IL-4 and total IgE in AA patients (particularly alopecia universalis, AU, and chronic patients) [31]. In addition, an elevated expression of Th1 cytokines (IFN- $\gamma$ ) and Th2 cytokines (IL-4 and IL-10) were observed in $\mathrm{C} 3 \mathrm{H} / \mathrm{HeJ}$ AA mice [32]. These findings differ from our results demonstrating decreased production of IL-4 in patients with AA. However, there is some evidence in the literature for a reduction of IL-4 production by patients and mice species that display the AA [5].

These disparities may in part depend on multiple factors such as the type of disease, disease activity and treatment [30-33]. These factors may affect some aspects of the immune system which may result in an altered Th1/Th2-balance and the cytokines they release. The main goal of the current study was to evaluate patients with new-onset AA and who had not received any treatment at all. The results indicated that the mRNA expression levels of T-bet and IFN- $\gamma$ were 
strikingly elevated in the PBMCs of our patients. This suggests that Th1 bias in Th1/Th2 immune response may play a vital role in disease induction.

\section{Conclusions}

The current research indicates mRNA expression of Th1-specific transcription factors (T-bet) and cytokines (IFN- $\gamma$ ) are predominant in the AA. As a result, Th1 immune responses may play an essential role in disease induction.

\section{References}

1. Alzolibani, A. A.: Epidemiologic and genetic characteristics of alopecia areata (part 1). Acta Dermatovenerol Alp Panonica Adriat 20, 191-198 (2011).

2. Giordano, C. N., Sinha, A. A.: Cytokine pathways and interactions in alopecia areata. Eur J Dermatol 23, 308-318 (2013).

3. Teraki, Y., Imanishi, K., Shiohara, T.: Cytokines in alopecia areata: Contrasting cytokine profiles in localized form and extensive form (alopecia universalis). Acta Derm Venereol 76, 421-423 (1996).

4. Tembhre, M. K., Sharma, V. K.: T-helper and regulatory T-cell cytokines in the peripheral blood of patients with active alopecia areata. Br J Dermatol 169, 543-548 (2013).

5. Katagiri, K., Arakawa, S., Hatano, Y.: In vivo levels of IL-4, IL-10, TGF-betal and IFNgamma mRNA of the peripheral blood mononuclear cells in patients with alopecia areata in comparison to those in patients with atopic dermatitis. Arch Dermatol Res 298, 397 401 (2007).

6. Hoffmann, R., Wenzel, E., Huth, A., van der Steen, P., Schäufele, M., Henninger, H. P., Happle, R.: Cytokine mRNA levels in Alopecia areata before and after treatment with the contact allergen diphenylcyclopropenone. J Invest Dermatol 103, 530-533 (1994).

7. Murphy, K. M., Reiner, S. L.: The lineage decisions of helper T cells. Nat Rev Immunol 2, 933-944 (2002).

8. Szabo, S. J., Kim, S. T., Costa, G. L., Zhang, X., Fathman, C. G., Glimcher, L. H.: A novel transcription factor, T-bet, directs Th1 lineage commitment. Cell 100, 655-669 (2000).

9. Gemmell, E., Seymour, G. J.: Cytokines and T cell switching. Crit Rev Oral Biol Med 5, 249-279 (1994).

10. Romagnani, S.: Regulation of the T cell response. Clin Exp Allergy 36, 1357-1366 (2006).

11. Vanaki, E., Ataei, M., Sanati, M. H., Mansouri, P., Mahmoudi, M., Zarei, F., Jadali, Z.: Expression patterns of $\mathrm{TH} 1 / \mathrm{TH} 2$ transcription factors in patients with guttate psoriasis. Acta Microbiol Immunol Hung 60, 163-174 (2013).

12. Tan, E., Tay, Y. K., Goh, C. L., Chin Giam, Y.: The pattern and profile of alopecia areata in Singapore-A study of 219 Asians. Int J Dermatol 41, 748-753 (2002).

13. Gilhar, A., Paus, R., Kalish, R. S.: Lymphocytes, neuropeptides, and genes involved in alopecia areata. J Clin Invest 117, 2019-2027 (2007). 
14. Gilhar, A.: Collapse of immune privilege in alopecia areata: Coincidental or substantial? J Invest Dermatol 130, 2535-2537 (2010).

15. McElwee, K. J., Gilhar, A., Tobin, D. J., Ramot, Y., Sundberg, J. P., Nakamura, M., Bertolini, M., Inui, S., Tokura, Y., King, L. E., Duque-Estrada, B., Tosti, A., Keren, A., Itami, S., Shoenfeld, Y., Zlotogorski, A., Paus, R.: What causes alopecia areata? Exp Dermatol 22, 609-626 (2013).

16. Chiricozzi, A., Zhang, S., Dattola, A., Cannizzaro, M. V., Gabellini, M., Chimenti, S., Nistico, S. P.: New insights into the pathogenesis of cutaneous autoimmune disorders. J Biol Regul Homeost Agents 26, 165-170 (2012).

17. Kroemer, G., Hirsch, F., González-García, A., Martínez, C.: Differential involvement of Th1 and Th2 cytokines in autoimmune diseases. Autoimmunity 24, 25-33 (1996).

18. Nakamura, M., Jo, J., Tabata, Y., Ishikawa, O.: Controlled delivery of T-box21 small interfering RNA ameliorates autoimmune alopecia (Alopecia Areata) in a $\mathrm{C} 3 \mathrm{H} / \mathrm{HeJ}$ mouse model. Am J Pathol 172, 650-658 (2008).

19. Ito, T., Hashizume, H., Shimauchi, T., Funakoshi, A., Ito, N., Fukamizu, H., Takigawa, M., Tokura, Y.: CXCL10 produced from hair follicles induces Th1 and Tc1 cell infiltration in the acute phase of alopecia areata followed by sustained Tc1 accumulation in the chronic phase. J Dermatol Sci 69, 140-147 (2013).

20. Katagiri, K., Arakawa, S., Hatano, Y.: In vivo levels of IL-4, IL-10, TGF-beta1 and IFNgamma mRNA of the peripheral blood mononuclear cells in patients with alopecia areata in comparison to those in patients with atopic dermatitis. Arch Dermatol Res 298, $397-$ 401 (2007).

21. Tembhre, M. K., Sharma, V. K.: T-helper and regulatory T-cell cytokines in the peripheral blood of patients with active alopecia areata. Br J Dermatol 169, 543-548 (2013).

22. Hoffmann, R., Wenzel, E., Huth, A., van der Steen, P., Schäufele, M., Henninger, H. P., Happle R.: Cytokine mRNA levels in Alopecia areata before and after treatment with the contact allergen diphenylcyclopropenone. J Invest Dermatol 103, 530-533 (1994).

23. Arca, E., Musabak, U., Akar, A., Erbil, A. H., Tastan, H. B.: Interferon-gamma in alopecia areata. Eur J Dermatol 14, 33-36 (2004).

24. Kasumagic-Halilovic, E., Prohic, A., Karamehic, J.: Serum concentrations of interferongamma (IFN-g) in patients with alopecia areata: Correlation with clinical type and duration of the disease. Med Arh 64, 212-214 (2010).

25. Zöller, M., McElwee, K. J., Vitacolonna, M., Hoffmann, R.: The progressive state, in contrast to the stable or regressive state of alopecia areata, is reflected in peripheral blood mononuclear cells. Exp Dermatol 13, 435-444 (2004).

26. Freyschmidt-Paul, P., McElwee, K. J., Hoffmann, R., Sundberg, J. P., Vitacolonna, M., Kissling, S., Zöller, M.: Interferon-gamma-deficient mice are resistant to the development of alopecia areata. Br J Dermatol 155, 515-521 (2006).

27. Nakamura, M., Jo, J., Tabata, Y., Ishikawa, O.: Controlled delivery of T-box21 small interfering RNA ameliorates autoimmune alopecia (alopecia areata) in a $\mathrm{C} 3 \mathrm{H} / \mathrm{HeJ}$ mouse model. Am J Pathol 172, 650-658 (2008).

28. Rückert, R., Hofmann, U., van der Veen, C., Bulfone-Paus, S., Paus, R.: MHC class I expression in murine skin: Developmentally controlled and strikingly restricted intraepithelial expression during hair follicle morphogenesis and cycling, and response to cytokine treatment in vivo. J Invest Dermatol 111, 25-30 (1998). 
29. Paus, R., Slominski, A., Czarnetzki, B. M.: Is alopecia areata an autoimmune-response against melanogenesis-related proteins, exposed by abnormal MHC class I expression in the anagen hair bulb? Yale J Biol Med 66, 541-554 (1993).

30. Teraki, Y., Imanishi, K., Shiohara, T.: Cytokines in alopecia areata: contrasting cytokine profiles in localized form and extensive form (alopecia universalis). Acta Derm Venereol 76, 421-423 (1996).

31. Attia, E. A., El Shennawy, D., Sefin, A.: Serum interleukin-4 and total immunoglobulin E in nonatopic alopecia areata patients and HLA-DRB1 typing. Dermatol Res Pract 2010, 503-587 (2010).

32. McElwee, K. J., Hoffmann, R.: Alopecia areata - Animal models. Clin Exp Dermatol 27, 410-417 (2002).

33. Zöller, M., McElwee, K. J., Vitacolonna, M., Hoffmann, R.: The progressive state, in contrast to the stable or regressive state of alopecia areata, is reflected in peripheral blood mononuclear cells. Exp Dermatol 13, 435-444 (2004). 